\title{
MEMS based Wheel Chair for Physically Challenged Persons
}

\author{
K. Vidyasagar \\ ECE Dept, SSIT \\ Sai Spurthi Institute of \\ Technology \\ B.Gangaram, Sathupally, India
}

\author{
M. Sundarao \\ ECE Dept, SSIT \\ Sai Spurthi Institute of \\ Technology \\ B.Gangaram, Sathupally, India
}

\author{
M. Sumalatha \\ ECE Dept, SSIT \\ Sai Spurthi Institute of \\ Technology \\ B.Gangaram, Sathupally, India
}

\begin{abstract}
With the advancement of science and Technology an innovative mechanism is adopted to provide the assistance for physically challenged personalities. Spinal card injury persons and physically challenged persons required human assistance to move from one point to another point. Electronics interfaced Wheel chair had designed to move without any assistance. Micro Elelctro Mechanical Systems (MEMS) based accelerometer sensor is used to direct the movement of the device. The wheel chair may move forward, backward, left and right directions based on the output signal of the MEMS device. Two 'Jonson' geared motors are attached to the geared sector assembly. PIC16F72 micro controller is used to release the appropriate signals to the motor driving circuit. The developed wheel chair is best suited to meet the challenges of the physically challenges personalities.
\end{abstract}

\section{Keywords}

MEMS, Wheel chair \& PIC16F72

\section{INTRODUCTION}

Assistive technology for physically challenged personalities had wide scope in present research era. Micro Elelctro Mechanical systems are adopted as sensing devices. The sensors may be positioned to sense the head movement or to sense the gestures of the hand. This work considered the angle of tilt of the arm in order to determine the movement direction of the wheel chair. The span of the sensor output signal is 1.8 Volts to 3 Volts is normalized as an axis angle of ' 0 ' to ' 180 ' Degrees. $\mathrm{X}$ and $\mathrm{Y}$ axis is considered with reference to the $\mathrm{Z}$ axis. Geared sector assembly is specifically designed for free movement of the wheel chair. The driving gear is welded to the high torque geared motor shaft. The driven wheel is welded to the actual wheel of the wheel chair. This developed working model is tested with various loads. This model is developed to provide the assistance for polio effected department student.

\section{LITERATURE SURVEY}

This paper describes the gesture based wheel chair direction control. An accelerometer had used to sense the direction of the wheel chair. The author did not implement the proposed mechanism physical wheel chair [1].

This paper describes the gesture based wheel chair for direction control of the wheel chair. MEMS sensor is used to sense the direction to be activated.PIC Micro controller is used to regulate the operations. The author developed a circuit but the results produced did not provide the velocity of the wheel chair and the response of the device [2].
The author used (ADXL330) based sensing device for direction determination of the wheel chair. AT 89S52 Microcontroller was used to regulate the operations. The author did not provided the experimental results for implementation of the developed work. The author also not developed a proto type working model [3].

This paper provided the theoretical overview on different methodologies adopted to develop the automatic wheel chair. The author not focused on the experimental and simulation results [4].

The author considered a MEMS sensor for position sensing. This paper also describes the methodology adopted to develop the control circuit [5].

This paper developed a methodology for proto type wheel chair. The author considered anti collision system to safeguard the physically challenged personality and surveillance camera is equipped for image acquisition and a metal detection sensor is provided to detect the explosives [6].

This paper developed a working model with the support of Atmel microcontroller to move the wheel chair in all the directions using hand gestures. The author estimated the time taken to travel a specified distance with various load conditions [7].

This paper studied an acceleration sensor to direct the wheel chair to move in all possible directions [8].

This paper used ARM 7 microcontroller to regulate the movements of the wheel chair. The author developed a control circuitry using arm 7[9].

\section{HARDWARE IMPLEMENTATION 3.1 MEMS Sensor}

ADXL335 is used as a 3-Axis accelerometer MEMS sensor. The output signal of this sensor is drawn between $1.8 \mathrm{~V}$ to $3 \mathrm{~V}$ for $\mathrm{X}$ and $\mathrm{Y}$ axis. Static acceleration gravity is measured by tilting the MEMS Sensor. The change of output voltage is depending on the change in the supply voltage. The tilt position of the sensor caused to produce the output signal in order to determine the motion of the wheel chair. The output signal of the MEMS Sensor is scale normalized as shown in table 3.1. This signal is processed using the microcontroller to enable the motion of the wheel chair. 
Table 3.1 MEMS output signal Vs motion direction

\begin{tabular}{|l|l|l|l|}
\hline S.NO & $\begin{array}{l}\text { MEMS Output } \\
\text { signal (V) }\end{array}$ & $\begin{array}{l}\text { XY plane } \\
\text { Angle } \\
\text { (degrees) }\end{array}$ & $\begin{array}{l}\text { Motion } \\
\text { direction }\end{array}$ \\
\hline 1 & 1.8 & 0 & Forward \\
\hline 2 & 2.1 & 45 & backward \\
\hline 3 & 2.4 & 90 & Stop \\
\hline 4 & 2.7 & 135 & Right \\
\hline 5 & 3.0 & 180 & left \\
\hline
\end{tabular}
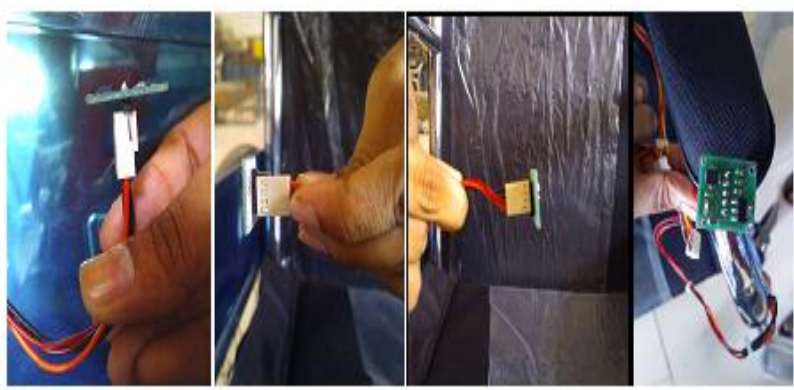

Fig 3.1 Different Orientations of the MEMS Sensor

\subsection{Control UNIT}

The analog output of the MEMS Sensor is digitized using Analog to digital converter. This digitized signal will be given as an input signal to the microcontroller (PIC16F72) for further processing. The processed output signal of the microcontroller causes to drive the motor driving circuitry (ULN2003). Electromagnetic relays are used to switch the motion of the wheel chair forward, backward, left and right. The relay functioning is depending on the signal drawn at the output stage of the ULN2003.

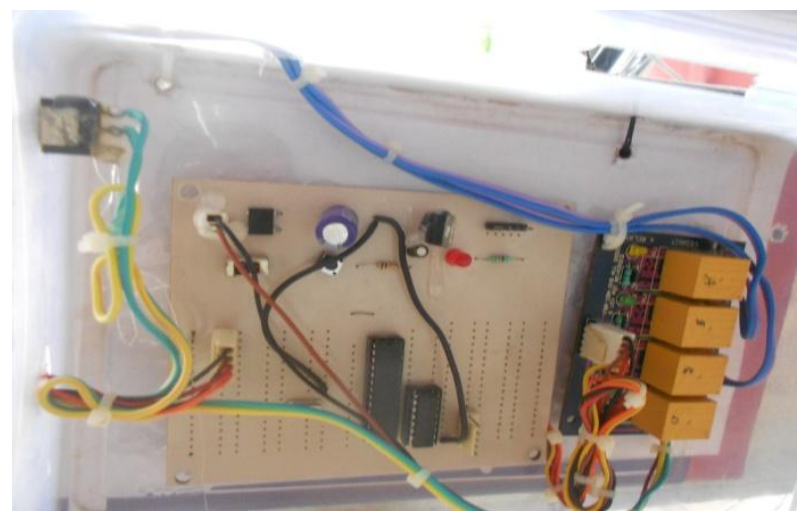

Fig 3.2 Control Circuit of the wheel chair

\subsection{Relay Unit}

The output port lines of the microcontroller are used to interface input pins of the relay. The logic Low results in a logic high output of the relay. The normally open contact is connected to the load applied. Logic Zero applied at the input pin of the relay causes to develop logic high at the output line. Then the relay is not energized. Logic 'high' at the input line cause to develop logic 'Zero' at the output line. Then the relay is energized. The armature switches from normally closed position to normally open position. This enables the on state of the motor assembly.

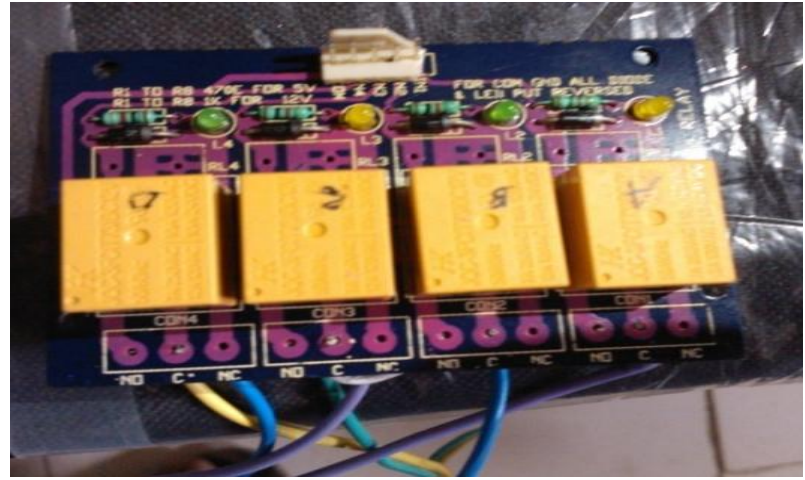

Fig.3.3 Relay assembly of the wheel chair.

Table 3.2 Relay Board Input-Output Combinations

\begin{tabular}{|c|c|c|c|c|}
\hline Specifications/Directions & Forward & Backward & $\begin{array}{c}\text { Right } \\
\text { Turn }\end{array}$ & $\begin{array}{c}\text { Left } \\
\text { Turn }\end{array}$ \\
\hline $\begin{array}{c}\text { Common 1(IN-1) } \\
\text { Left motor +Ve(Blue } \\
\text { Wire)-Yellow LED }\end{array}$ & $\begin{array}{c}\mathbf{1} \\
\text { (High) }\end{array}$ & $\begin{array}{c}\mathbf{0} \\
\text { (Low) }\end{array}$ & $\begin{array}{c}\mathbf{1} \\
\text { (High) }\end{array}$ & $\begin{array}{c}\mathbf{0} \\
\text { (Low) }\end{array}$ \\
\hline $\begin{array}{c}\text { Common 2(IN-2) } \\
\text { Left motor -Ve(Violet } \\
\text { Wire)-Green LED }\end{array}$ & $\begin{array}{c}\mathbf{0} \\
\text { (Low) }\end{array}$ & $\begin{array}{c}\mathbf{1} \\
\text { (High) }\end{array}$ & $\begin{array}{c}\mathbf{0} \\
\text { (Low) }\end{array}$ & $\begin{array}{c}\mathbf{1} \\
\text { (High) }\end{array}$ \\
\hline $\begin{array}{c}\text { Common 3(IN-3) } \\
\text { Right motor +Ve(Blue } \\
\text { Wire)-Yellow LED }\end{array}$ & $\begin{array}{c}\mathbf{1} \\
\text { (High) }\end{array}$ & $\begin{array}{c}\mathbf{0} \\
\text { (Low) }\end{array}$ & $\begin{array}{c}\mathbf{0} \\
\text { (Low) }\end{array}$ & $\begin{array}{c}\mathbf{1} \\
\text { (High) }\end{array}$ \\
\hline $\begin{array}{c}\text { Common 4(IN-4) } \\
\text { Right motor -Ve(Violet } \\
\text { Wire) -Yellow LED }\end{array}$ & $\begin{array}{c}\mathbf{0} \\
\text { (Low) }\end{array}$ & $\begin{array}{c}\mathbf{1} \\
\text { (High) }\end{array}$ & $\begin{array}{c}\mathbf{1} \\
\text { (High) }\end{array}$ & $\begin{array}{c}\mathbf{0} \\
\text { (Low) }\end{array}$ \\
\hline
\end{tabular}

\section{SOFTWARE IMPLEMENTATION}

Algorithm is developed to move the wheel chair forward, backward, left and right directions.

\subsection{Algorithm}

Step1: Initialize the motor 1

$$
\begin{aligned}
& \text { Delay= } 10 \mathrm{~m} \mathrm{sec} \\
& \text { If Pin_C0 outputs Low and } \\
& \qquad \text { Pin_ D1 outputs high }
\end{aligned}
$$

Then

Direction of motor is clock wise (forward=1)

Else

Direction of the motor is anticlockwise

(Backward=0).

Step 2: Provide delay $100 \mathrm{~m} \mathrm{sec}$

Step3: Initialize the motor 2

If

Pin_C3 outputs low and

Pin_D0 outputs high 
Direction of motor is clock wise (forward=1)

Else

Direction of the motor is anticlockwise (Backward=0).

Step4: Provide delay $100 \mathrm{~m} \mathrm{sec}$

Step5: Initialize ADC ports and clock interval

Step6: Initialize the Pulse Width Modulation (PWM)

Duty cycle $=620$

Step 7: Set up TIMER 2 (T2)

Step8: Read the data from ADC Channel (MEMS Sensor)

Step9: $\mathrm{X}$ - Axis of the MEMS sensor is $=\mathrm{X}$

Y-Axis of the MEMS sensor is $=\mathrm{Y}$

Step 10: If ( $\mathrm{y}<80$ degrees $)$

Output Logic 1 on PIN_D2

Then

Motor 1 and Motor 2 are 'Off'

Else

if $(y>100$ degrees $)$

Output logic '1' on Pin_D3

Then

Motor 1 and motor 2 are 'ON'

Else

If $(x<80$ degrees $)$

Output logic ' 1 ' on Pin_C4

Motor 1 is 'On'

Motor 2 is ' $O f f$ '

Else

if $(x>100$ degrees $)$

Motor ' 1 'is 'Off'

Motor ' 2 ' is ' $\mathrm{ON}$ '

Step11: Reset the duty cycle to 'Zero'

Step12: Output logic '0' on Pin D_2, D_3 and C_4, C_5

Step 13: Go to Step 8

\section{RESULT AND ANALYSIS}

The experiments were conducted with variable load conditions. The signal transportation delay is influenced on the developed working model due to mechanical rigidness of the motor assembly and frictional forces. This delay is influenced with increasing the load. The signal transportation is represented in Fig 5.1

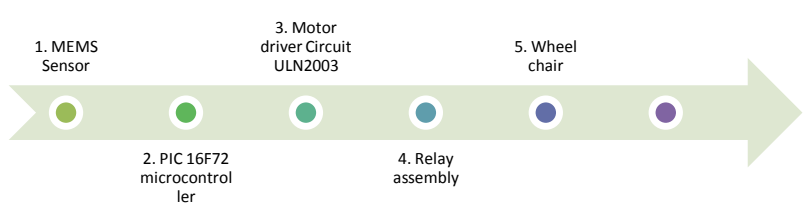

Fig. 5.1 Flow of signals from input to output

The movement of the hand is sensed by the MEMS accelerometer sensor and the corresponding signal based on the angle of elevation is sent to the micro controller. The signal is processed in the micro controller and corresponding directions are given to the motors. The developed model had been tested with an increasing load from $50 \mathrm{Kg}$ to $90 \mathrm{Kg}$. The velocity of the wheel chair considerably reduced with increasing load. The table 5.1 represents the velocity of the developed working model with various load conditions. The distance travelled for various directions is ' 3.3 ' meters constant value.

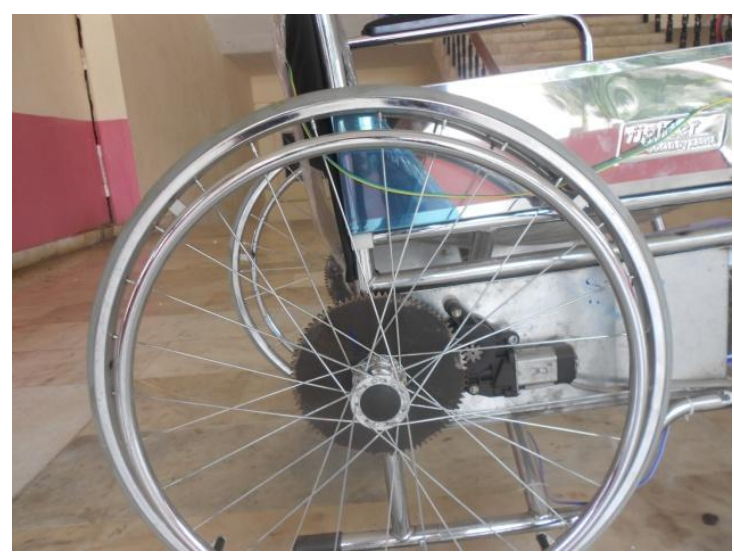

Fig 5.2 Geared assembly of the wheel

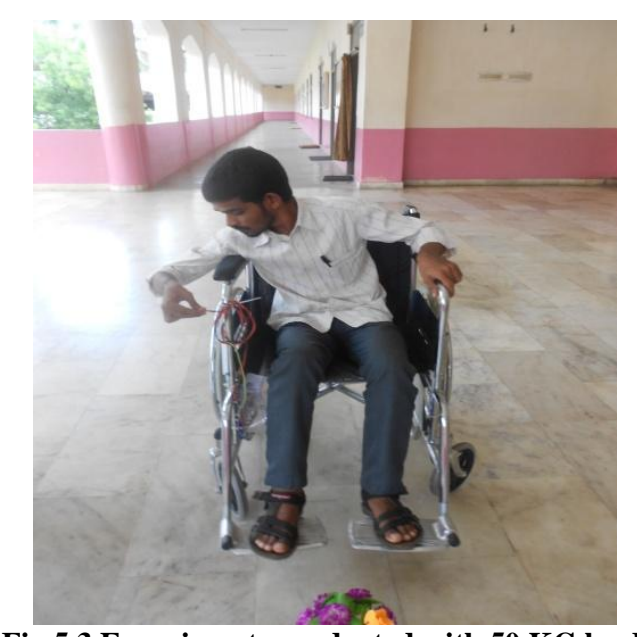

Fig 5.3 Experiments conducted with 50 KG load

Table 5.1 Velocity of wheel chair for $50 \mathrm{Kg}$ load For $50 \mathrm{Kg} \mathrm{Load}$

\begin{tabular}{|l|l|l|}
\hline $\begin{array}{l}\text { Wheel } \\
\text { chair } \\
\text { direction }\end{array}$ & $\begin{array}{l}\text { Time } \\
\text { (Sec) }\end{array}$ & $\begin{array}{l}\text { Velocity of the } \\
\text { wheel chair } \mathbf{~} / \mathbf{s}\end{array}$ \\
\hline Forward & 17.33 & 0.190 \\
\hline
\end{tabular}




\begin{tabular}{|l|l|l|}
\hline Backward & 14.73 & 0.2240 \\
\hline Right & 14.20 & 0.2323 \\
\hline Left & 14.76 & 0.2235 \\
\hline
\end{tabular}

Table 5.2 Velocity of wheel chair for $60 \mathrm{Kg}$ load For 60 KG load

\begin{tabular}{|l|l|l|}
\hline $\begin{array}{l}\text { Wheel } \\
\text { chair } \\
\text { direction }\end{array}$ & $\begin{array}{l}\text { Time } \\
\text { (Sec) }\end{array}$ & $\begin{array}{l}\text { Velocity of the } \\
\text { wheel chair }\end{array}$ \\
\hline Forward & 19.41 & 0.1700 \\
\hline Backword & 17.62 & 0.1872 \\
\hline Right & 16.89 & 0.1953 \\
\hline Left & 16.72 & 0.1973 \\
\hline
\end{tabular}

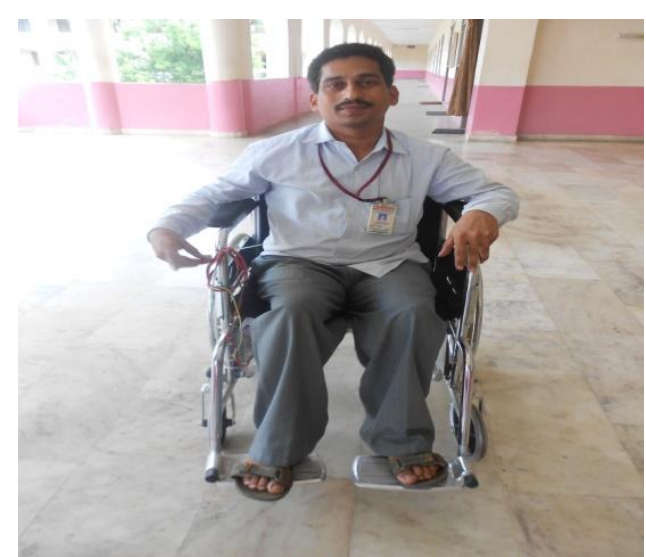

Fig 5.3 Experiments conducted with 60 KG load

Table 5.3 Velocity of wheel chair for $70 \mathrm{Kg}$ load For $70 \mathrm{Kg}$ Load

\begin{tabular}{|l|l|l|}
\hline $\begin{array}{l}\text { Wheel } \\
\text { chair } \\
\text { direction }\end{array}$ & $\begin{array}{l}\text { Time } \\
(\mathrm{Sec})\end{array}$ & $\begin{array}{l}\text { Velocity of the } \\
\text { wheel chair }\end{array}$ \\
\hline Forward & 19.78 & 0.16683 \\
\hline Backword & 18.52 & 0.1781 \\
\hline Right & 17.87 & 0.1846 \\
\hline Left & 17.91 & 0.1842 \\
\hline
\end{tabular}

Table 5.1, Table 5.2, Table 5.3, Table 5.4 Depicts the velocity of the wheel chair and its response for various directions is progressively good up to $70 \mathrm{KGs}$ load. The signal delay is progressively increased over $70 \mathrm{KGs}$ load. The graph represented in the fig 5.2 concludes that the developed working model is best suited for load up to $70 \mathrm{KGs}$.

\section{CONCLUSION}

The developed working model is best suited for physically challenged personalities. The results tested with various loads. The model produced favorable results to move in all directions with maximum load of $70 \mathrm{KGs}$. The motor load driving capacity is to be reconsidered in future scope of the research work.
In future this model is also equipped with physiological sensing parameter devices like Body temperature, heart rate meter, Blood pressure meter and Electro cardio gram (ECG). For attentive of the trained nurse and even the doctor these physiological parameters need to be transmitted to the doctor mobile for safeguarding the health of the physically challenged personalities.

\section{ACKNOLEDGEMENT}

The author would like to extend sincere thanks to the Principal Dr. Chennupati Vijayakumar Sai Spurthi Institute of Technology for his constant encouragement. The author also would like to extend sincere thanks to the management for proving the necessary funds and infrastructure to develop the working model.

\section{REFERENCES}

[1] Javajji Veeraiah et.al, "Accelerometer Based Gesture Recognisation for Wheel Chair Direction Control sing ZIGBEE Protocol" , International Journal of Technological Exploration and Learning, vol 2(2) : 104108, April 2013.

[2] Diksha Goyal and Dr. S.P.S. Saini," Accelerometer Based Hand Gesture Controlled Wheelchair", International Journal on Emerging Technologies 4(2): 15-20, 2013.

[3] Sukhmeet Kaur and Hem Chand Vashist, "Sukhmeet Kaur1 and Hem Chand Vashist2" , Advance in Electronic and Electric Engineering, Volume 3( 2): 227 232, 2013.

[4] Mohammed Asgar et.al, "Automated innovative wheel chair ", International Journal of Information Technology Convergence and Services (IJITCS) Vol.3, No.6, December 2013.

[5] Shaik Meeravali, M . Aparna, "Design and Development of a Hand-glove Controlled Wheel Chair Based on MEMS" , International Journal of Engineering Trends and Technology (IJETT) - Volume 4( 8): 3706-3712, August 2013

[6] N.V.MaruthiSagar," MEMS Based Gesture Controlled Robot Using Wireless Communication “,International Journal of Engineering Trends and Technology, Vol 14 (4): 185-188, Aug 2014

[7] Mohammed Ismail.B et.al ," Head Gesture Based Control of Wheelchair for a Paralysed Person in an Indoor Environment", international journal of innovative research in electrical, electronics, instrumentation and control engineering, Vol. 2(10):2079-2083, October 2014

[8] Prof. Vishal V.Pande, et.al, "Hand Gesture Based Wheelchair Movement Control for Disabled Person Using MEMS", Journal of Engineering Research and Applications, Vol 4 (4): 152-158, April 2014.

[9] B. Ramana Reddy, J. V. Sharma, "Movement based and Voice enabled Device Switching for basic needs of Physically Challenged Persons", International Journal of Science and Research, Vol. 2(3):137-139, March 2013 


\section{AUTHOR PROFILE}

K.Vidyasagar Received B.Tech degree in Instrument Technology from Andhra University College of Engineering Visakhapatnam, M.E from P.S.G .Tech Coimbator. He is now a research scholar under the guidance of Dr. A. Bhujangarao, Andhra University. His current research interests include image processing in biomedical instrumentation and related embedded systems

M.Sundararao received B.Tech degree in Electronics and Communication Engineering in sai Spurthi Institute of
Technology, Sattupalli, M.Tech from Gudlavalleru Engineering College, Gudlavalleru. His current research interest is embedded medical applications and signal processing.

M.Sumalatha received in ECE from NCET, Vijayawada, M.Tech from Anurag Engineering college, Kodad. She is now a research scholar at JNTU kakianada. Her current research interests include signal processing and related VLSI technology. 